\title{
Editorial
}

'Aqualisation' of neuraxis: Wondrous neuraqua CSF 1

Manu Kothari, Atul Goel

\section{View and Review}

Organization of neurology services in India: Unmet needs and the way forward

Mandaville Gourie-Devi

\section{Original Articles}

\section{Endoscopic management of brain abscesses}

Yad Ram Yadav, Mallika Sinha, Neha, Vijay Parihar

Pattern of cerebellar perfusion on single photon emission computed tomography in subcortical hematoma:

A clinical and computed tomography correlation

Jayantee Kalita, Usha K. Misra, Prasen Ranjan, P. K. Pradhan

Imaging features in Hirayama disease

Hemant A. Sonwalkar, Rakesh S. Shah, Firosh K. Khan, Arun K. Gupta, Narendra K. Bodhey, Surjith Vottath,

Sukalyan Purkayastha

Delayed habituation in Behcet's disease

Sefa Gulturk, Melih Akyol, Hulusi Kececi, Sedat Ozcelik, Ziynet Cınar, Ayse Demirkazık

Erythrocyte indicators of oxidative changes in patients with graded traumatic head injury

Chandrika D. Nayak, Dinesh M. Nayak, Annaswamy Raja, Anjali Rao

Repeat gamma knife radiosurgery for recurrent or refractory trigeminal neuralgia

Liang Wang, Zhen-wei Zhao, Huai-zhou Qin, Wen-tao Li, Hua Zhang, Jian-hai Zong,

Jian-Ping Deng, Guo-dong Gao

Taste dysfunction in vestibular schwannomas

Rabi Narayan Sahu, Sanjay Behari, Vimal K. Agarwal, Pramod J. Giri, Vijendra K. Jain

Surgical management of traumatic intracranial pseudoaneurysms: A report of 12 cases

Xiang Wang, Jin-Xiu Chen, Chao You, Min He

Expression of truncated dystrophin cDNAs mediated by a lentiviral vector

Sun Shunchang, Chen Haitao, Chen Weidong, He Jingbo, Peng Yunsheng

Gamma knife radiosurgery for glomus jugulare tumors: Therapeutic advantages of minimalism in the skull base

Manish S. Sharma, A. Gupta, S. S. Kale, D. Agrawal, A. K. Mahapatra and B. S. Sharma 


\section{Case Reports}

Subarachnoid hemosiderin deposition after subarachnoid hemorrhage on T2*-weighted MRI correlates with the location of disturbed cerebrospinal fluid flow on computed tomography cisternography

Yoshifumi Horita, Toshio Imaizumi, Yuji Hashimoto, Jun Niwa

Anesthesia management of awake craniotomy performed under asleep-awake-asleep technique using laryngeal mask airway: Report of two cases

Gadhinglajkar Shrinivas Vitthal, Rupa Sreedhar, Mathew Abraham

High cervical C3-4 'disc' compression associated with basilar invagination

Atul Goel

Short-lasting unilateral neuralgiform headache with conjunctival injection and tearing: Response to antiepileptic dual therapy

Ravi Gupta, Manjeet S. Bhatia

Correlation of autism with temporal tubers in tuberous sclerosis complex

Kavitha Kothur, Munni Ray, Prahbhjot Malhi

Non-traumatic carotid dissection and stroke associated with anti-phospholipid antibody syndrome:

Report of a case and review of the literature

Benzi M. Kluger, Richard L. Hughes, C. Alan Anderson, Kathryn L. Hassell

Osteoma of anterior cranial fossa complicated by intracranial mucocele with emphasis on its radiological diagnosis

Jinhu Ye, Hui Sun, Xin Li, Jianping Dai

Vasospasm after transsphenoidal pituitary surgery: A case report and review of the literature

Manish Kumar Kasliwal, Ravinder Srivastava, Sumit Sinha, Shashank S. Kale, Bhawani S. Sharma

Chondromyxoid fibroma of the seventh cervical vertebra

Ashish Jonathan, Vedantam Rajshekhar, Geeta Chacko

Acute progressive midbrain hemorrhage after topical ocular cyclopentolate administration

Tarkan Calisaneller, Ozgur Ozdemir, Erkin Sonmez, Nur Altinors

\section{Letters to Editor}

Digital subtraction angiography laboratory with inbuilt CT (DynaCT): Application during intracranial anurysm embolization

Concomitant tuberculous and pyogenic cerbellar abscess in a patient with pulmonary tuberculosis

Drug complianceafter stroke andmyocardial infarction:Is complementary medicine an issue? 


\section{Neurology India}

Free full text at www.neurologyindia.com and www.bioline.org.br/ni

Multiple intracranial developmental venous anomalies associated with complex orbitofacial

vascular malformation

Nitrofurantoin-induced peripheral neuropathy:A lesson to be re-learnt

Posterior longitudinal ligament cyst as a rare cause of lumbosacral radiculopathy with positive straight

leg raising test

Aqueductal stenosis caused by an atypical course of a deep collector vein draining bilateral cerebellar developmental venous anomalies

Recovery of increased signal intensity of the cervical cord on magnetic resonance imaging after surgery for spontaneous spinal epidural hematoma causing hemiparesis

Simultaneous thalamic and cerebellar hypertensive hemorrhages

\section{Neuroimages}

MRI and MRA in spontaneous intracranial arterial dissection

S. Raghavendra, Sanjeev V. Thomas, Krishnamoorthy Thamburaj, Bejoy Thomas

Shunt catheter migration into pulmonary arteries

Miikka Korja, Matti K. Karvonen, Arto Haapanen, Reijo J. Marttila

Susceptibility weighted imaging in holohemispheric venous angioma with cerebral hemiatrophy

The copies of the journal to members of the association are sent by ordinary post. The editorial board, association or publisher will not be responsible for non-receipt of copies. If any of the members wish to receive the copies by registered post or courier, kindly contact the journal's / publisher's office. If a copy returns due to incomplete, incorrect or changed address of a member on two consecutive occasions, the names of such members will be deleted from the mailing list of the journal. Providing complete, correct and up-to-date address is the responsibility of the members. Copies are sent to subscribers and members directly from the publisher's address; it is illegal to acquire copies from any other source. If a copy is received for personal use as a member of the association/society, one cannot resale or give-away the copy for commercial or library use. 


\title{
Organization of neurology services in India: Unmet needs and the way forward
}

\author{
Mandaville Gourie-Devi \\ Emeritus Professor of Neurology, Institute of Human Behavior and Allied Sciences, Chairperson of Department of Neurophysiology and Senior \\ Consultant in Neurology, Sir Gangaram Hospital, New Delhi, India
}

\begin{abstract}
Recognition of the magnitude of the burden and disability and mortality consequent to neurological disorders has led to global initiatives of declaring them as a "global epidemic", emphasizing public health approach and integration of neurology care with general health care. Epidemiological transition with increase in neurological disorders in India, the gross mismatch between the need and the available trained manpower and infrastructural facilities are posing challenges to health planners and policy makers for providing neurological care to the community. Alternative approaches of optimal utilization of rural, community health, satellite clinic and district models of the health care with close interaction with tertiary centres, nongovernmental agencies and private sector may facilitate achieving the goal of taking neurology care to the 'unreached'.
\end{abstract}

Key words: Neurological disorders, burden, prevalence, disability, health care models, neurological services

\section{Global Scenario of burden of Neurological Disorders}

The recent report published by the World Health Organization "Neurological disorders, public health challenges" states that about one billion people worldwide suffer from neurological disorders and that 6.8 million people die annually from these disorders. ${ }^{[1]}$ The spectrum of neurological disorders includes epilepsy, stroke, headache, Alzheimer's disease and other dementias, Parkinson's disease, multiple sclerosis, brain injuries, neuroinfections etc. Stroke is the second most common cause of mortality and a major cause of disability.

Neurological disorders accounted for $4.2 \%$ of the global burden of disease in $1996^{[2]}$ which has significantly increased to $6.29 \%$ in 2005 assessed by the disability adjusted life years (DALYs) for common neurological disorders (epilepsy, dementia, Parkinsons's disease, multiple sclerosis, cerebrovascular disease, poliomyelitis, tetanus, meningitis, Japanese encephalitis). ${ }^{[1]}$ Further rise in burden is expected and by 2030 it is estimated to be $6.77 \%$ [Table 1]. An increase in mortality due to neurological disorders from $11.67 \%$ of the total mortality in 2005 to $12.22 \%$ in 2030 is also anticipated. ${ }^{[1]}$ Thus neurological disorders can be considered as a global epidemic calling for a global campaign to promote advocacy, improve awareness, education and prevention and to enhance neurology care. ${ }^{[3]}$

The prevalence of neurological disorders globally in the year 2005 was 155.36 per 1000 population, nearly a third of them due to nutritional deficiency and toxins [Table 2]..$^{[1]}$ While dementia is estimated to increase in 2030, the decrease in prevalence rate of all neurological disorders to 143.5 can be attributed to control of infectious diseases and improved nutritional status. Based on the projections of United Nations that by 2025, there will be 1.2 billion elderly people in the world and $71 \%$ will be living in the developing countries, it is expected that neurological disorders in the elderly will show a significant rise, particularly in the developing world.

Neurological disorders pose a great challenge to healthcare in developing countries in view of limited resources and manpower that are inadequate to tackle the increasing burden. Recognizing the urgency to meet the challenges, a "Committee on Nervous System Disorders in Developing Countries" formed by the Board on Global Health, Institute of Medicine, National Academy of Sciences, USA (the author was a member of this committee) reviewed the magnitude, pattern, causes, prevention and low-cost treatment of common neurological disorders. The committee strongly recommended integration of neurological care into the public health system and emphasized that this approach is a recognized way of increasing coverage through an affordable and accessible service involving the community. ${ }^{[4]}$ 
Table 1: Burden of neurological disorders, in disability adjusted life years (DALYs) in the World

\begin{tabular}{|c|c|c|c|c|c|c|}
\hline Year & \multicolumn{3}{|c|}{2005} & \multicolumn{3}{|c|}{2030} \\
\hline Population & \multicolumn{3}{|c|}{6441919466} & \multicolumn{3}{|c|}{7917115397} \\
\hline Total DALYs & \multicolumn{3}{|c|}{1469610066} & \multicolumn{3}{|c|}{1526745574} \\
\hline Disorder & DALYs & $\%$ & $\begin{array}{c}\text { Per } \\
100000 \\
\text { population }\end{array}$ & DALYs & $\%$ & $\begin{array}{c}\text { Per } \\
100000 \\
\text { population }\end{array}$ \\
\hline Epilepsy & 7307975 & 0.50 & 113.44 & 7441536 & 0.49 & 93.99 \\
\hline Alzheimer and other dementias & 11077525 & 0.75 & 171.96 & 18394267 & 1.20 & 232.34 \\
\hline Parkinson's disease & 1616523 & 0.11 & 25.09 & 2015065 & 0.13 & 25.45 \\
\hline Multiple sclerosis & 1509696 & 0.10 & 23.44 & 1648303 & 0.11 & 20.82 \\
\hline Migraine & 7659687 & 0.52 & 118.90 & 7596089 & 0.50 & 95.95 \\
\hline Cerebrovascular disease & 50784770 & 3.46 & 788.35 & 60864051 & 3.99 & 768.77 \\
\hline Poliomyelitis & 115167 & 0.01 & 1.79 & 13261 & 0.00 & 0.17 \\
\hline Tetanus & 6422611 & 0.44 & 99.70 & 3173636 & 0.21 & 40.09 \\
\hline Meningitis & 5336882 & 0.36 & 82.85 & 2038968 & 0.13 & 25.75 \\
\hline Japanese encephalitis & 561038 & 0.04 & 8.71 & 149931 & 0.01 & 1.89 \\
\hline Total for all neurological disorders & 92391874 & 6.29 & 1434.23 & 103335108 & 6.77 & 1305.21 \\
\hline
\end{tabular}

Source ${ }^{[1]}$

Table 2: Prevalence of neurological disorders in the world

\begin{tabular}{|c|c|c|c|c|}
\hline $\begin{array}{l}\text { Year } \\
\text { Population }\end{array}$ & & & & \\
\hline Disorder & Number & Per 1000 & Number & Per 1000 \\
\hline Epilepsy & 39891898 & 6.19 & 50503933 & 6.38 \\
\hline Alzheimer and other dementias & 24446651 & 3.79 & 44016718 & 5.56 \\
\hline Parkinson's Disease & 5223897 & 0.81 & 7236712 & 0.91 \\
\hline Multiple sclerosis & 2492385 & 0.39 & 3279199 & 0.41 \\
\hline Migraine & 326196121 & 50.64 & 412894420 & 52.15 \\
\hline Cerebrovascular disease & 61537499 & 9.55 & 76826249 & 9.70 \\
\hline Neuroinfections & 18169479 & 2.82 & 13290180 & 1.68 \\
\hline Nutritional and neuropathies & 352494535 & 54.72 & 285369403 & 36.04 \\
\hline Neurological injuries & 170382211 & 26.45 & 242728912 & 30.66 \\
\hline Total & 1000834676 & 155.36 & 1136145726 & 143.50 \\
\hline
\end{tabular}

Source $^{[1]}$

\section{Emerging Health Scenario in India}

India, with a population of more than one billion, is facing new challenges in the health sector due to a paradigm shift in disease burden. Added to the burden of communicable diseases with emerging and re-emerging infections and nutritional deficiency disorders, there is epidemiological transition with increasing incidence of non-communicable disorders (NCD), some attributable to lifestyle and others to increased life expectancy. ${ }^{[5]}$ Amongst the NCDs, neurological disorders have been recognized to lead to significant mortality, morbidity, disability and socioeconomic loss. Epilepsy, cerebrovascular disorders, migraine, dementia, Parkinson's disease, motor neuron disorder, traumatic injuries, brain damage due to birth trauma, neuromuscular disorders, demyelinating disorders and neurological disorders consequent to nutritional deficiency and exposure to neurotoxic substances contribute to significant burden. Further, widely prevalent infections of the nervous system such as tuberculosis, malaria, cysticercosis and viral infections, particularly Japanese encephalitis and HIV also lead to neurological deficits.
The unique characteristics of neurological disorders such as chronicity, progressive degeneration, limited therapeutic options and lack of specific treatment for many diseases, further contribute to the disease burden and morbidity. The effect of stigma associated with epilepsy, particularly in developing countries, on disease burden cannot be easily estimated since it leads to complexities in diagnosis and management and a large treatment gap. ${ }^{[6]}$ Redeeming features are recent developments including (i) advances in diagnostic modalities of imaging, immunological and molecular tests, (ii) introduction of new therapeutic strategies such as thrombolysis, immunomodulating agents (immunoglobulins, interferon) and (iii) use of new drugs for treatment of epilepsy, Parkinson's disease and neuroinfections which have ushered a sea change in the clinical practice of neurology, enabling early diagnosis and more effective treatment leading to improved outcome of the disease.

\section{Indian Scenario of Neurological Disorders}

Population-based neuroepidemiologic surveys during the last 15 years, using standardized WHO 
questionnaire with modifications, ${ }^{[7-9]}$ in different regions of the country have shown the prevalence rate of neurological disorders to vary from 967 to 4070 per 100000 population [Table 3]. ${ }^{[10-16]}$ The Parsis, a distinct ethnic group, have an unusually high prevalence rate, but they do not represent the general population of the country. In these surveys, infections of the nervous system and traumatic injuries of brain, spinal cord and peripheral nerves have not been included and therefore it would be an underestimate of the total burden of neurological disorders.

All age groups are affected with peaking in the elderly above 60 years of age. In India according to the 2001 census $^{[17]}$ there are 77 million people above the age of 60 years and it is expected that by 2025 there will be a huge increase to 177 million with consequent significant rise in age-related disorders such as cerebrovascular disorders, Parkinson's disease and dementia. Contradicting the perception of the policy-makers and administrators that neurological disorders are seen mostly in the urban population, neuroepidemiologic surveys have demonstrated that the prevalence in the rural population is significantly higher than in the urban population. In a large communitybased survey in Bangalore of a population of 102557 comprising an urban population of 51502 and rural population of 51055, the prevalence rates were 2190 and 4070 , respectively, with a ratio of $1: 1.85 .^{[15]}$ This fact is critical for planning infrastructure and trained manpower for providing equitable neurology care in the country. ${ }^{[18]}$ Prevalence of some common disorders is shown in Table 4. Based on the prevalence studies, it may be estimated that in India there are 20 to 30 million people with neurological disorders and the common disorders include epilepsy ( 6 to 8 million), headache (1012 million), strokes ( 1 to 2 million). Transient ischemic attacks are not included in surveys and hence the actual burden of cerebrovascular disorders will be higher than these projected figures.

Special mention needs to be made regarding care of people with epilepsy in view of the associated stigma, the myths and misconceptions about the nature of the disorder ${ }^{[19,20]}$ and the consequent burden to the patients and their family members, factors which are not considered while determining the disability adjusted life years (DALYS). Some of the crucial factors leading to a wide treatment gap of 38 to $80 \%$ in the country ${ }^{[19,21]}$ are stigma associated with epilepsy preventing patients seeking medical advice, lack of awareness that epilepsy is a brain disorder and that it can be treated. It is therefore important to move forward from descriptive neuroepidemiologic studies to interventional strategies for prevention and treatment of neurological disorders. ${ }^{[22]}$

\section{Disability Consequent to Neurological Disorders}

Neurorehabilitation forms an integral component of neurology services since disability due to neurological disorders, unlike other diseases, is a major issue. The disabilities are categorized as affecting mobility, disturbance of cognition and behavior, causing pain, disturbance of consciousness and function. ${ }^{[23]}$ Further, a specific neurological disability may result from a combination of different impairments or a single

\begin{tabular}{|c|c|c|c|c|c|}
\hline Author & Place & Year & Nature of population & Population surveyed & Prevalence rate/100000 \\
\hline Gourie-Devi[10] & Gowribidanur & 1987 & Rural & 57,660 & 1,382 \\
\hline Bharucha $^{[11]}$ & Bombay & 1987 & Urban & 851 (Parsis) & 9400 \\
\hline Kapoor $^{[12]}$ & Ballabgarh & 1989 & Rural & 48,798 & 3,487 \\
\hline Razdan $^{[13]}$ & Kuthar Valley & 1994 & Rural & 63,645 & 967 \\
\hline $\operatorname{Das}^{[14]}$ & Malda & 1996 & Rural & 37,286 & 2,856 \\
\hline \multirow[t]{3}{*}{ Gourie-Devi ${ }^{[9,15]}$} & Bangalore & 1996 & Total & $1,02,557$ & 3,126 \\
\hline & & 2004 & Rural & 51,055 & 4,070 \\
\hline & & & Urban & 51,502 & 2,190 \\
\hline
\end{tabular}

\begin{tabular}{|c|c|c|c|c|c|c|}
\hline \multirow{2}{*}{ Disorder } & Gourie-Devi & Bharucha & Kapoor & Razdan & Das & Gourie-Devi \\
\hline & 1987 & 1987 & 1989 & 1994 & 1996 & 2004 \\
\hline Epilepsy & 4.63 & 4.7 & 4.02 & 2.47 & 3.05 & 8.83 \\
\hline Headache & 1.73 & N.A & 16.95 & N.A & 18.58 & 11.19 \\
\hline $\begin{array}{l}\text { Stroke } \\
\text { Mental retardation and }\end{array}$ & 0.52 & 17.6 & 0.88 & 1.43 & 1.26 & 1.50 \\
\hline Cerebral palsy & 1.63 & 2.4 & 1.09 & 3.3 & 0.64 & 1.42 \\
\hline Parkinson's disease & 0.07 & 7.1 & N.A & 1.4 & 0.16 & 0.33 \\
\hline Peripheral neuropathy & 0.52 & 15.2 & N.A & 2.99 & 0.75 & 1.28 \\
\hline Post poliomyelites sequelae & 0.99 & N.A & 4.95 & 2.18 & 0.55 & 1.1 \\
\hline
\end{tabular}

NA-data not available 
impairment may lead to multiple disabilities. There are only a few published reports on the magnitude and severity of disability consequent to neurological disorders. There are two hospital-based studies and one community-based study. Taly and Chaudhuri ${ }^{[24]}$ in the hospital-based study at the National Institute of Mental Health and Neurosciences, Bangalore, observed that at discharge from the hospital 92\% of 1093 patients had disability with varying degree of severity. Follow-up after six months showed that the disability persisted in $79 \%$ but there was a slight favorable change with increase in the proportion of those with mild disability. However, there was significant impact on the quality of life since $80 \%$ of them required assistance for daily activities. In the other hospitalbased study at the Postgraduate Institute of Medical Education and Research, Chandigarh, Prabhakar et al., ${ }^{[25]}$ reported that 12 months after discharge from the hospital, $60 \%$ of 258 patients had either partial or no improvement or even worsening of the disability. Assessment using Dysfunction Analysis Questionnaire showed that there was significant dysfunction in social, vocational, personal, family and cognitive domains. ${ }^{[26]}$ The dysfunction varied across different neurological disorders and was more in the elderly. In the isolated report on community survey as a component of Bangalore Urban Rural Neuroepidemiological survey (BURN), disability assessment done using modified Barthel's index showed that $20 \%$ of 3128 persons identified with neurological disorders, had significant disability and it was twice more common in the rural region compared to the urban. ${ }^{[27]}$ These studies draw attention to the need for a comprehensive rehabilitation program for care of neurologically disabled people in the 'post-acute phase' so that they can function as useful citizens as stated in the policy statement by the World Health Organization. ${ }^{[28]}$ Apart from rehabilitation focused on motor, sensory and cognitive deficits there is a need for psychosocial rehabilitation and effective utilization of community resources. ${ }^{[29,30]}$

\section{Economic Burden of Neurological Disorders}

The economic aspects of the burden of neurological disorders include direct cost of outpatient care, drugs, emergency admissions, in-patient care and expenses for transport, particularly from remote areas to centers of healthcare and hospitals. Indirect costs are unemployment, under-employment, income lost by family members, disability-associated issues and excess mortality. Intangible costs are attributable to pain, disability and suffering. Economic burden of neurological disorders, with the exception of epilepsy, has not been determined in India. In a well-designed study by Thomas et al. ${ }^{[31]}$ conducted in six medical centers, one each from six states including Andhra
Pradesh, Gujarat, Kerala, Karnataka, Maharashtra and Tamil Nadu, the annual cost of epilepsy per patient was INR 13755. Based on this data and the number of people with epilepsy in the country, the economic burden was estimated to be INR 68.75 billion. An important issue emanating from this study was that the indirect costs of travel expenses to the hospital situated at a considerable distance and the consequent loss of productivity amounted to $14 \%$ of the total annual cost. In the absence of data for other neurological disorders, it may be assumed that the indirect cost would be almost similar. Providing neurology care at the level of the community at the "doorstep" will mitigate this problem to a considerable extent.

\section{Public Health Perspective}

Conventionally, the emphasis in neurological practice has been on meticulous clinical examination, logical interpretation of the clinical profile and systematic and thorough investigations followed by complete synthesis. Focus has been on research to understand the disease process, to develop new and more precise diagnostic techniques and novel therapeutic modalities. These approaches have indeed been highly rewarding and need to be vigorously pursued to find answers to research questions. Additionally, in view of the large burden of neurological disorders, a public health approach to provide primary healthcare at the community level and develop a robust system for referral of complex problems to specialists and centers of excellence has to be put in place. ${ }^{[32]}$ Close interaction of the health sector with politicians, administrators, economists and social scientists is the backbone of a public health model. The World Health Organization (WHO) had launched the initiative of "Neurology and Public Health" in 1993 with the goals: i) to draw attention to neurological illnesses and emphasize the frequency and severity of these disorders, ii) to acknowledge neurological disorders as public health problems, iii) to emphasize the possibilities for their prevention and iv) to ensure care and treatment for people with neurological illnesses at all levels, particularly at the primary level. To achieve these objectives, the approach was to promote a national and international policy for improving neurology care, to convince the governments to consider neurological disorders as a public health problem and to increase public awareness of neurological disorders. It was reiterated that (i) prevention of stroke through national intervention programs to reduce the risk factors of hypertension, diabetes mellitus, smoking, obesity, lifestyle modification, (ii) control of infestations such as cysticercosis and (ii) reduction of birth injuries which contribute to significant proportion of epilepsy, will be possible through public health approach. ${ }^{[32]}$

Through the collaborative effort of WHO and the World 
Federation of Neurology, the status of neurology care and the lacunae in manpower and facilities across 109 countries from the six WHO regions (Africa, Americas, Eastern Mediterranean, Europe, South-East Asia and Western Pacific) was published in the Neurology Atlas. ${ }^{[33]}$ Valuable data for neurological services at the primary level, availability of specialists, beds, specialized neurology services etc. obtained through questionnaire from one key person in each country, has been included (author was the key person for India). This crucial information will be very useful for rational formulation of policies and health planning to develop the required neurological services. ${ }^{[34]}$

\section{Organization and Delivery of Neurology Services}

The current scenario in the country is far from satisfactory with a gross mismatch of the burden of neurological disorders and the availability of trained neurologists, other essential health professionals and infrastructural facilities. The ratio of one neurologist for population varies widely among developed countries from one to two neurologists per 20000 to 100000; in developing countries the ratio is much higher at one neurologist for 3 to 5 million people and in many regions of the world there are no neurologists. ${ }^{[35]}$ In the US there is one neurologist per 26200 and in Africa it is one per $5,009,908$ [Table 4]. ${ }^{[36,37]}$ The scenario is grim in India with one neurologist for 3,200,000 in 1998, which has slightly improved to the current ratio of one neurologist for 1,250,000 and 800 neurologists for a population of more than one billion people [Table 5]. ${ }^{[38,39]}$

A high-powered committee was set up by Government of India, the Technology Information Forecasting and Assessment Council (TIFAC) to assess the technology and manpower requirements in various fields including health (author was a member of the subcommittee to assess the needs in neurology). ${ }^{[40]}$ Even with a modest expectation of one neurologist for 200,000, the requirement would be more than 5000 neurologists and since only 80 to 90 neurologists are trained annually in the country, half a century or more is likely to elapse before this goal is achieved. ${ }^{[39]} \mathrm{A}$ third or more of the

\begin{tabular}{lc}
\hline \multicolumn{1}{c}{ Table 5: Average population per neurologist } \\
\hline Country & Population \\
United States & 26200 \\
Canada & 53000 \\
United Kingdom & 164000 \\
Latin America & 202000 \\
Middle East & 613000 \\
Asia & 902000 \\
Sub-Saharan & \\
India & \\
1998 & 3200000 \\
2002 & 2180000 \\
Present position & 1250000 \\
\hline
\end{tabular}

neurologists are located in the metropolitan cities of Bangalore, Chennai, Delhi, Hyderabad, Kolkata and Mumbai and others in big towns but hardly any specialist care is available to the people in the rural areas. The exception to this bleak national scene is Kerala with 126 neurologists for a population of 31 million with a ratio of approximately $1: 250,000$ and reasonable distribution across 12 of 14 districts, with the sole exception of clustering of neurologists in the Trivandrum district (personal communication Dr. Abdul Salam Naha, President of Calicut Neurological Society). Keeping in view the constraints of specialist manpower, TIFAC recommended that there is a need to conceptualize and consider alternative strategies for organizing services at the peripheral, regional and tertiary levels [Table 6]. The crucial recommendations were to improve neurology care at all levels of the hierarchy of the health care pyramid, enhance manpower and meet the growing technology requirements. There is also an urgent need to upscale capacity-building by increasing the number of training institutes and the annual intake of candidates without compromising on the standard of training. It goes without saying that the place of neurology in the medical curriculum has to be expanded.

\section{Models for Delivery of Neurology Care}

The existing structure of the healthcare system in the country would influence the pattern of medical practice and consequently the care of people with neurological disorders. For developing models useful guidelines comprise, 1) policy statement to consider neurological disorders as a public health problem; 2) decentralization of care and development of resources and skills at the primary level; 3) close interaction between general practitioners, physician and specialist neurologist; 4) training in diagnosis and management of common and treatable neurological disorders (epilepsy, stroke, migraine, peripheral neuropathy, Parkinson's disease etc) for health providers; 5) ensuring continuity of care and adequate documentation of medical records; 6) adequate and regular supply of essential drugs; 7) establishing systems/network for referral of patients to tertiary centers for intensive and advanced diagnostic techniques and treatment; 8) partnership between governmental and nongovernmental agencies with focused goals of providing comprehensive neurology care and 9) spreading awareness and public education about neurological disorders with specific emphasis on

Table 6: Neurological Services for India by the year 2020

\begin{tabular}{lccc}
\hline Services & Population & Existing & Projected \\
Peripheral center & $2,000,000$ & Nil & 500 \\
Regional center & $10,000,000$ & 55 & 100 \\
Apex center & $50,000,000$ & 10 & 20
\end{tabular}


preventive aspects, particularly with reference to stroke and epilepsy.

Various models shown in Figure 1 are complementary to each other with 'bottoms up' approach and hierarchal level of expertise and facilities. ${ }^{[41]}$ A strong system of two-way communication needs to be in place with the care of the patient entrusted to the local physician after diagnostic tests and acute management has been completed and further line of treatment decided at the tertiary center.

\section{Rural model}

The prevalence of neurological disorders in the rural areas, as mentioned earlier, is almost twice that in the urban area and since $70 \%$ of India's population lives in the villages, of the estimated 20-30 million people with neurological disorders 15 to 20 million of them will be in the rural regions. ${ }^{[15]}$ Availability of neurology care at the village level would avoid the costs involved in travel, loss of wages during the period and most importantly delay in treatment. Rural models for providing neurology care with reference to epilepsy, implemented in Karnataka, West Bengal, Malawi, Kenya and Eucador have been found to be feasible, practicable and successful in achieving the desired goals. ${ }^{[42-46]}$ This concept can be expanded to include other common neurological disorders.

\section{Community health center model}

Most of the medical colleges and medical institutions have their peripheral Community Health Centers (CHC) which provide general healthcare and undertake immunization programs covering generally a population of 50000 to 100000 and some of them closely interact with primary health centers. Many of the CHCs also have mobile health services reaching out to interior villages. Resident doctors who provide healthcare can be trained to diagnose and treat common neurological disorders and the patients requiring more detailed investigations and management can be provided care at the parent institution. ${ }^{[47]}$

\section{Satellite clinic model}

Through a joint venture and active commitment of a tertiary institute, in this case the National Institute of

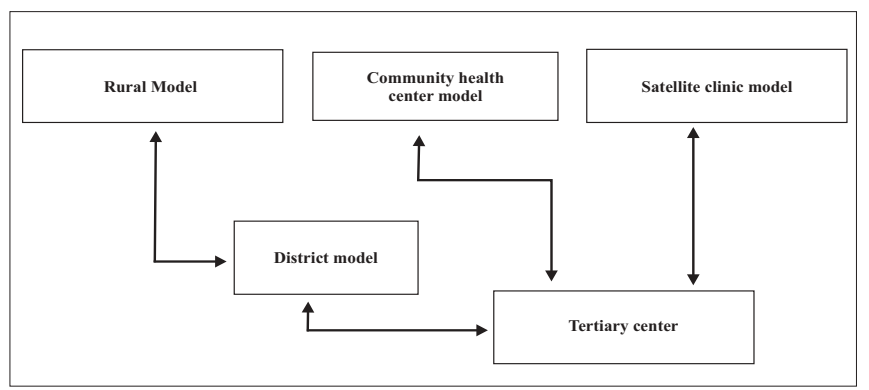

Figure 1: Models for delivery of neurological care to the communicy
Mental Health and Neurosciences, the local government agencies at the taluk/district level and nongovernmental agencies, neurology services were provided in five peripheral centers located within 50 to $100 \mathrm{~km}$ of the apex center through satellite outreach clinics. The clinical expertise of consultants combined with the facilities in the peripheral hospital and the contribution of free drugs by the NGOs for common neurological disorders during monthly camps at a fixed place and on q fixed day of the week, was found to be a viable model. ${ }^{[48]}$ It was observed that common neurological disorders such as epilepsy, migraine, peripheral neuropathy, movement disorders etc could be easily managed. Duplication of this model by other institutions will help in reaching out to smaller towns and villages.

\section{District model}

There are 593 districts in the country with population ranging from 1.5 to 2 million and it is estimated that there will be approximately 45000 to 60000 people with neurological disorders in a district. A district model for healthcare delivery has the advantages that it is an independent administrative unit and the administrative head, the district health officer, has powers for planning health-related activities, implementation and monitoring health programs at the district level. Intersectorial coordination is possible and all health programs of the primary health centers and taluks are under the jurisdiction of the district. The Bellary district model for mental healthcare has been shown to be feasible for the integration of mental healthcare with general health services and became the cornerstone of the National Mental Health Plan with implementation in 25 districts and currently plans are afoot to extend the program to cover 100 districts. Based on this experience, a district model of epilepsy care was developed by the author and colleagues with the support of WHO, essentially focusing on training of district medical officers in identification, diagnosis and treatment of epilepsy. ${ }^{[41,49,50]}$ Over a two-year period during six workshops 148 district medical officers from 11 states were trained and evaluation of the training program by comparison of pre-test to post-test questionnaire showed that there was significant improvement of knowledge, skills and confidence in providing care to people with epilepsy. Based on this road map, the experience emerging from mental health and epilepsy services can be translated to provide comprehensive neurology care by suitable modifications of the training modules.

\section{Tertiary center}

Facilities for neurology care are available in about 60 medical colleges, which may be considered as regional centers. It was planned in the TIFAC ${ }^{[39,40]}$ that by 2020 there should be at least double the number of centers. Presently there are 262 medical colleges ${ }^{[51]}$ and if 
facilities for neurology care are created in at least 50\% of the medical colleges, the defined goal of expanding neurology care and training of medical professionals can be achieved. Centers with advanced state-of-the-art facilities are now available in 10 apex centers. There is a need to increase these centers to at least 20 by the year 2020. All these figures pertain to the government sector only and since affordability is a major concern, the emphasis is on this sector. An increasing number of hospitals in the private sector are offering excellent care but at a prohibitive cost.

\section{Integration and Interaction of Models of Neurology Care}

It must be reiterated that the various models of neurology care suggested are not mutually exclusive but are complementary as shown in Figure 2. While common neurological disorders like migraine and epilepsy can be easily managed at the peripheral centers, cerebrovascular disorders after the initial emergency care can be referred to the tertiary center which is functionally linked and in proximity to the peripheral centers. The respective role of medical professionals and specialist neurologists may be defined as shown in Figure 2. It is envisaged that nodal neurologists at the tertiary centers, be it at the national or state level, would have a crucial responsibility of training medical professionals in addition to providing neurology care of a high order. The necessary infrastructure for providing

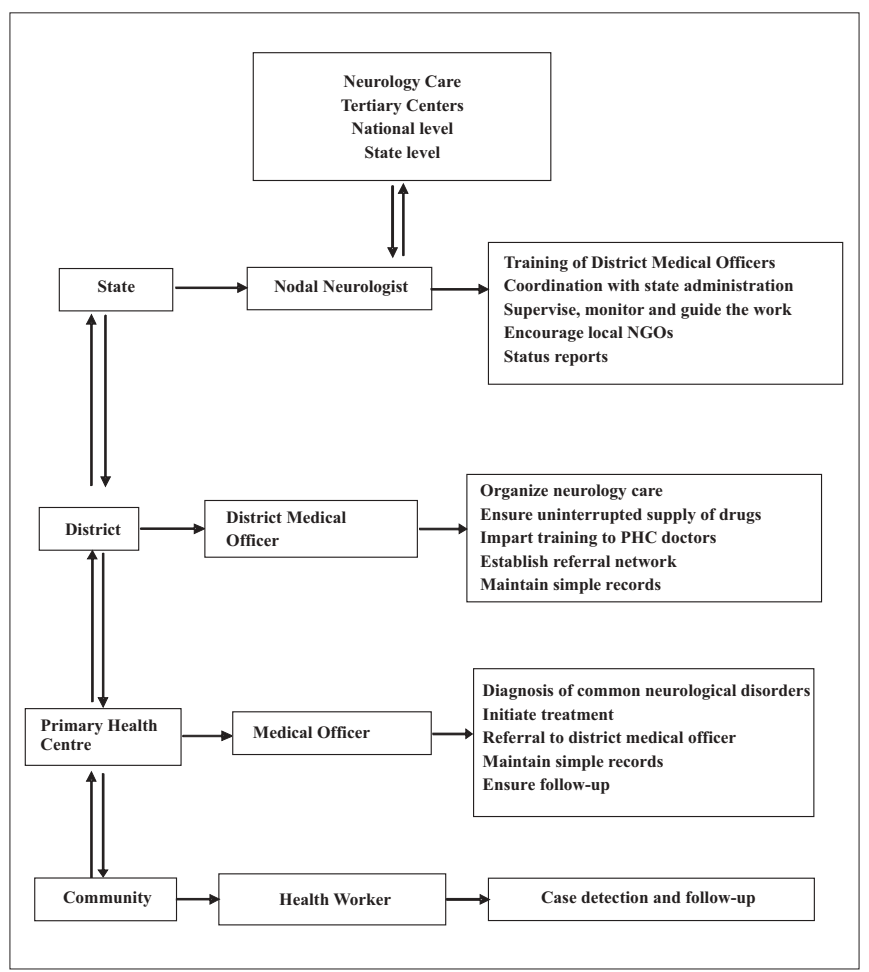

Figure 2: Integration of neurology care at various levels of health care neurological services along with regular supply of drugs at different levels of the healthcare pyramid ranging from basic essential facilities at the primary care level to advanced state-of-the-art facilities at the tertiary centers along with appropriate manpower has to be established. Enlisting the support of nongovernmental agencies and the private sector is also an essential component of providing neurology care. This network if operationally effective and efficient, can lead to a national program for neurology care, as envisaged and enunciated by WHO and the World Federation of Neurology. ${ }^{[33]}$ On the anvil is the agenda to harness telemedicine, which currently is restricted to a few institutes in the country and exploit the full potential to enhance the clinical network between the tertiary and primary care centers.

\section{Conclusions}

It has been brought into focus that neurological disorders need to be recognized as a public health problem and advocacy be promoted to draw the attention of health planners and administrators in view of the magnitude of the problem of 30 million or more people with neurological disorders in the country. The grossly inadequate number and misdistribution of neurologists with the major proportion concentrated in metropolis and bigger towns and lack of infrastructure has deprived a large proportion of the patients, particularly the economically challenged and those in rural and remote areas, of neurology care. Alternative models of neurology care drawing upon the rich experience of healthcare delivery through rural community health centers, satellite clinics and district models with close interaction with the specialist neurologists in tertiary institutes, having a pivotal role in training the medical professionals in the peripheral centers, form the backbone of national program for neurology care in the country. Concentrated action in this direction is an urgent necessity.

\section{Foot note}

The author is currently Member of the World Health Organization Expert Advisory panel on Neurosciences. Earlier served as (i) Convener, Sub-group on Neurological, Neurosurgical, Psychiatric Disorders and Addictions, Technological Information, Forecasting and Assessment Council (TIFAC) for 2020, Department of Science and Technology, New Delhi; (ii) Member of Committee on "Neurology in Public Health", World Health Organization;(iii) Member of Committee on Nervous System Disorders in Developing Countries" Board on Global Health, Institute of Medicine, National Academy of Sciences, USA and (iv) Resource person for India for development of "Atlas: Country resources for neurological disorders" World Health Organization and World Federation of Neurology. 


\section{References}

1. World H ealth Organsiation. N eurological disorders: public health challenges. Geneva; 2006.

2. Murray CJ , L opez AD, editors. The global burden of disease: A comprehensive assessment of mortality and disability from diseases, injuries and risk factors in 1990 and projected to 2020. Global burden of disease and injury series, vol.1. Cambridge (MA): $\mathrm{H}$ arvard School of Public $\mathrm{H}$ ealth on behalf of the World $\mathrm{H}$ ealth Organization and the World B ank; 1996.

3. B ergen DC, Silberberg D. Nervous system disorders. Arch Neurol 2002;59:1194-6.

4. J ablensky A, J ohnson R, B unney W J r, Cruz M, Durkin M, Familusi J , et al. N eurological, psychiatry and developmental disorders: Committee on nervous system disorders in developing countries (B oard on Global $\mathrm{H}$ ealth, Institute of Medicine). National Academy Press: Washington DC; 2001.

5. Reddy KS, Shah B, Verghese $C$, Ramdoss A. Responding to the threat of chronic diseases in India. $L$ ancet 2005;366:1744-9.

6. Meinardi H, Scott RA, Reis R, Sander J W; ILAE Commission on the developing world. The treatment gap in epilepsy: The current situation and ways forward. E pilepsia 2001;42:136-49.

7. Gourie-D evi M, Rao VN, Prakashi R. A protocol to detect neurological disorders in the community. Indian J Med Res 1988;88:443-9.

8. Gourie-D evi M, Gururaj G, Satishchandra P. N euroepidemiology in developing countries. Manual for descriptive studies. B angalore: $N$ ational Institute of M ental $\mathrm{H}$ ealth and $\mathrm{N}$ euro Sciences (N I M H AN S P ublication N o.33); 1994

9. Gourie-D evi M, Gururaj G, Satishchandra P, Subbakrishna DK. $N$ euroepidemiological pilot survey of an urban population in a developing country: A study in Bangalore, South India. Neuroepidemiology 1996:15:313-20.

10. Gourie-Devi M, Rao VN, Prakashi R. Neuroepidemiological study in semi-urban and rural areas in South India: Pattern of neurological disorders including motor neurone disease. In: Gourie-D evi M, editor. M otor neurone disease: Global clinical patterns and international research. Oxford and IB H : N ew Delhi; 1987. p. 11-21.

11. B harucha NE, B harucha E P, D astur H D, Schoenberg B S. Pilot survey of the prevalence of neurological disorders in the Parsi community of B ombay. Am J Prev Med 1987;3:293-9.

12. Kapoor SK, B anerjee AK. Prevalence of common neurological diseases in a rural community of India. Indian J Com Med 1989;14:171-6.

13. Razdan S, Kaul RH, M otta A, K aul S, B hatt RK. Prevalence and pattern of major neurological disorders in rural Kashmir (India) in 1986. N euroepidemiology 1994;13:113-9.

14. Das SK, Sanyal K. N euroepidemiology of major neurologic disorders in rural B engal. N eurol India 1996;44:47-58.

15. Gourie-D evi M, Gururaj G, Satishchandra P, Subbakrishna DK. Prevalence of neurological disorders in B angalore, India: A community-based study with a comparison between urban and rural areas. N euroepidemiology 2004;23:261-8.

16. Gourie-D evi M, Gururaj G, Satishchandra P. N euroepidemiology in I ndia: Development during three decades. NIMH ANS J 1999;17:379-87.

17. Census of I ndia- Census data; $\mathrm{N}$ ational summary data. 2001. Available from: http://www.censusindia.gov.in.

18. Gourie-D evi M, Gururaj G, Satishchandra P. N euroepidemiology: Present insights and future prospects. N I MHAN J 1999;17:423-37.

19. Radhakrishnan K, Pandian J D, Santoshkumar T, Thomas SV, D eetha TD, Sarma PS, \& al. Prevalence, knowledge, attitude and practice of epilepsy in Kerala, South India. E pilepsia 2000;41:1027-35.

20. Gourie-D evi M, Anderson DW, Rao VN. Neuroepidemiologic survey in a developing country: Some questions and answers. In: Anderson DW, editor. N euroepidemiology: A tribute to B ruce Schoenberg. CR C Press: B oston; 1991. p. 13-23.

21. Gururaj G, Reddy GN, Shariff IA, Subbakrishna DK. Factors associated with utilization of services by epilepsy patients in rural areas: A descriptive study. NIMH ANS J 1994;12:135-40.

22. Gourie-D evi M, Gururaj G, Satishchandra P. Interventional neuroepidemiology: From descriptive studies to interventions. In: Venkataraman S, editor. Progress in Clinical N eurosciences. N eurological Society of I ndia: N ew Delhi; 1999. p. 225-41.
23. H ewer RL. The epidemiology of disabling neurological conditions. In: Greenwood R, B arnes MP, M cM illan RM, Ward CD, editors. N eurological rehabilitation. Churchill L ivingstone: $\mathrm{N}$ ew York; 1993. p. 3-12.

24. Taly AB, Chaudhuri J R. N eurorehabilitation: An emerging concept. In: Venkataraman S, editor. Progress in clinical neurosciences. N eurological Society of India: N ew Delhi; 1997. p. 427-37.

25. Prabhakar S, Chopra J S, Pershad D. Physical disability and psychosocial functioning in neurological disorders: A follow up study. Neurol India 1991;39:63-6.

26. Pershad D, Verma SK, M alhotra S, M alhotra S, Das K, K han H A. Further validation of the dysfunction analysis questionnaire. Indian J Clin Psychol 1983;10:445-50.

27. Gururaj G, Gourie-D evi M, Taly AB, Satishchandra. E pidemiology of neurological disorders and consequent disabilities-Indian Scenerio: I mplications for rehabilitation policies and programmes. In: Taly AB, $\mathrm{N}$ air K PS, Murali T, editors. N eurorehabilitation principles and practice. $\mathrm{N}$ ational Institute of Mental $\mathrm{H}$ ealth and Neuro Sciences: B angalore; 1998. p. 1-35.

28. World $\mathrm{H}$ ealth Organsiation Technical Report Series, 744. H ospital and H ealth for all. Geneva; 1987. p. 87-8.

29. Prakashi R, Gourie-D evi M. Scope of social work services in neurological setting: I nitial observations. J M ed Psy Social Work 1987;1:15-20.

30. Prakashi R, Gourie-Devi M. Rehabilitation of neurologically disabled persons, I mplications for community participation. Rehabilitation Asia 1988;29:8-12.

31. Thomas SV, Sarma PS, Alexander M, Pandit L, Shekhar L, Trivedi C, $€$ al. E conomic burden of epilepsy in India. E pilepsia 2001;42:1052-60.

32. L eonardi M. Neurology and public health in developing countries. In: Clifford RF, editor. Recent advances in tropical neurology. E Isevier Science P ublishers BV: Amsterdam, the N etherlands; 1995. p. 1-6.

33. World $\mathrm{H}$ ealth Organization, World Federation of $\mathrm{N}$ eurology. Atlas: Country resources for neurological disorders. Geneva; 2004.

34. J anca A, Aarli J A, Prilpko L, D ua T, Saxena S, Saraceno B. WH O/WF N survey of neurological services: A worldwide perspective. J Neuro Sci 2006;247:29-34

35. Aarli J A. N eurology and WH O: Challenges and issues-A report. World N eurol 2002;17:10-1

36. B ergen DC. World F ederation of N eurology Task F orce on N eurological Services: Training and distribution of neurologists worldwide. J Neuro Sci 2002;198:3-7.

37. B ower J H, Zeneba G. N eurologic services in the nations of Africa. N eurology 2005;64:412-5.

38. Singhal BS. N eurology in developing countries: A population perspective. Arch Neurol 1998;55:1019-21.

39. Gourie-D evi M. M edical technologies for neurological sciences. In: Mathew $L$, editor. Technology management in health care. $D$ efence bioengineering and electromedical laboratory (DE BE L): B angalore; 1998. p. 62-7.

40. Technology I nformation Forecasting and Assessment Council (TIFAC) report on $\mathrm{H}$ ealth care, technology vision 2020. Department of Science and Technology: N ew Delhi; 1996.

41. Gourie-D evi M, Satishchandra P, Gururaj G. Delivery of epilepsy care to the community: Towards the national epilepsy control programme. In: Agarwal SP, Goel DS, I chhpujani RL, Salhan RN, Shrivastava S, editors. Mental health. An Indian perspective 1946-2003. Directorate General of $\mathrm{H}$ ealth Services Ministry of $\mathrm{H}$ ealth and Family Welfare: $\mathrm{N}$ ew Delhi; 2004. p. 295-305.

42. Mani KS, Rangan G, Srinivas HV, Sridharan VS, Subbakrishna DK. E pilepsy control with phenobarbital or phenytoin in rural south India: The Yelandur study. L ancet 2001;357:1316-20.

43. Pal DK, Das T, Chaudhury G, J ohnson AL, N eville BG. Randomised controlled trial to assess acceptability of phenobarbital for childhood epilepsy in rural I ndia. L ancet 1998;351:19-23.

44. Watts $A E$. A model for managing epilepsy in rural community in Africa. B MJ 1989;298:805-7.

45. Feksi AT, Kaamugisha J, Sanders J W, Gatiti S, Shorvon SD. Comprehensive primary healthcare: Anti-epileptic drug treatment programme in rural and semi urban K enya. L ancet 1991;337:406-9.

46. Placensia M, Sander J W, Shorvon SD, Paredes V, Suarez J , Cascante SM . Anti-epileptic drug treatment in a community healthcare setting in Northern E cuador: A prospective 12-month assessment. E pilepsy Res 
1993;14:237-44.

47. Sriram TG, Chandrasekhar CR, Moily S. E pilepsy in primary care: A study of follow-up profile and response to treatment. Nimhans J r 1998;8:133-7.

48. Reddy GN, Channabasavanna SM, Gourie-D evi M, Das BS, Prabhu GG, Shariff IA, \&al. Extension of the mental health services by satellite clinics as a model. N I MH AN S J $r$ 1986;4:71-5.

49. Gourie-D evi M, Satishchandra P, Gururaj G. N ational workshop on public health aspects of epilepsy for senior personnel of state health departments in India. Ann Indian Acad N eurol 1999;2:43-8.
50. Gourie-D evi M, Satishchandra P, Gururaj G. E pilepsy in primary care: E pilepsy control program in India: A district model. E pilepsia 2003;44:58-62.

51. Central B ureau of health intelligence, 2007. Available from: http://www. cbhidghs.nic.in.

Accepted on 12-01-2008

Source of Support: Nil, Conflict of Interest: None declared. 